\title{
Public Transport Use and Satisfaction by International Students and Researchers
}

\author{
Mayara Moraes Monteiro ${ }^{1,2, *(\mathbb{D})}$, João de Abreu e Silva ${ }^{3}\left(\mathbb{D}\right.$, Jesper Bláfoss Ingvardson ${ }^{2}$, Otto Anker Nielsen ${ }^{2}$ \\ and Jorge Pinho de Sousa ${ }^{1}$
}

Citation: Monteiro, M.M.; de Abreu e Silva, J.; Ingvardson, J.B.; Nielsen, O.A.; Pinho de Sousa, J. Public Transport Use and Satisfaction by International Students and Researchers. Sustainability 2021, 13, 8417. https://doi.org/10.3390/ su13158417

Academic Editors: Socrates Basbas, Tatiana Campisi, Nick Stamatiadis, Kh Md Nahiduzzaman and Andreas Nikiforiadis

Received: 7 July 2021

Accepted: 25 July 2021

Published: 28 July 2021

Publisher's Note: MDPI stays neutral with regard to jurisdictional claims in published maps and institutional affiliations.

Copyright: (c) 2021 by the authors. Licensee MDPI, Basel, Switzerland. This article is an open access article distributed under the terms and conditions of the Creative Commons Attribution (CC BY) license (https:/ / creativecommons.org/licenses/by/ $4.0 /)$.
1 INESC TEC, Faculdade de Engenharia da Universidade do Porto, R. Dr. Roberto Frias, 4200-465 Porto, Portugal; jorge.p.sousa@inesctec.pt

2 Transport Division, Department of Technology, Management and Economics, DTU—Technical University of Denmark, Bygningstorvet 116B, 2800 Kongens Lyngby, Denmark; jbin@dtu.dk (J.B.I.); oani@dtu.dk (O.A.N.)

3 CERIS, Department of Civil Engineering, Architecture and Georesources, Instituto Superior Técnico, Universidade de Lisboa, 1049-001 Lisboa, Portugal; jabreu@tecnico.ulisboa.pt

* Correspondence: maymmo@dtu.dk

\begin{abstract}
Travel behavior adaptations resulting from international temporary relocation is understudied, despite their increasing relevance. The scarce published literature on the subject overlooks the local contexts and ignores aspects related to the adaptation processes and motivations. This study aims to partially fill this gap by addressing the travel behavior adaptation of international students and researchers, focusing on public transport (PT) frequency of use and satisfaction. To investigate this, a Bayesian Structural Equation Model was estimated using data collected from a tailor-made online survey answered by temporary international exchange students and researchers. The model confirms that (i) travel behavior habit in the city of origin influences the residential location choice in the host city; (ii) the higher the frequency of PT use in the city of origin, the higher the PT use in the host city; (iii) the residential location in the host city affects individuals' frequency of PT use and satisfaction; (iv) perceiving technology as helpful to move around leads to perceiving the PT system as easier to use at the beginning of the stay; (v) perceiving the PT as easier to use, leads to a higher frequency of its use and a higher level of satisfaction with the PT system.
\end{abstract}

Keywords: international students; temporary residents; transnational relocation; travel behavior adaptation; satisfaction with public transport; ICT

\section{Introduction}

Travel behavior adaptation resulting from international temporary relocation is a very understudied topic, despite its increasing relevance during the last years [1,2]. It is possible to have a dimension of the growing importance of this topic by looking at longitudinal data related to the ERASMUS program in Europe, which shows that while the exchange program supported a total of 3244 students in 1987 [3], in 2019, almost 940,000 people have studied, trained, or volunteered abroad [4]. Furthermore, the Erasmus program expects that between 2021 and 2027, about 10 million individuals will participate in mobility activities abroad under the program [5]. This means a constant increase in the mobile/temporary population in cities, for which cities need to prepare in order to provide a good experience and remain as attractive destinations.

The lack of studies on this topic can be partially explained by the difficulties in studying such a contemporary issue, which is associated with ongoing societal changes [6]. The impact of residential relocation on travel behavior adaptation has been somehow examined in the literature of mobility biographies (e.g., [7-12]), but mainly focusing on short-distance relocations, where the changes experienced by movers are limited to neighborhood-related qualities. Contrasting with that, long-distance relocations usually result in individuals dealing with changes in the entire transport system and mobility culture [13-16]. From the 
perspective of travel behavior, the scarce published literature on the subject overlooks the contexts associated with where people come from and arrive at, ignoring the processes and motivations individuals' have for the spatial and travel behavior adaptation in the hosting place (e.g., $[17,18])$. Thus, our understanding of the travel behavior preferences and choices of international students and researchers is limited. This study partially fills this gap by investigating the travel behavior adaptation of international university students and researchers in the light of what is described so far in the general literature on travel behavior adaptation following a residential relocation. We focus our analysis on their Public Transport (PT) usage and satisfaction because individuals tend to rely on the mobility options provided by the host city for short-term stays $[16,19]$ rather than invest in a private individual transport mode that has a higher investment cost.

In our analysis, we consider aspects related to the city of origin and host city that can influence individuals' travel behavior, such as (i) past travel behavior and habits, which can be indicators of preferences and predispositions established in previous locations; (ii) choice of residential location, as the local infrastructure can influence travel behavior and previous preferences can lead to a specific residential location choice; (iii) perceived initial easiness in using PT, as it can stimulate people to rely on PT or search for alternatives to move around in the host city; and (iv) perceptions regarding technology use as helpful for mobility purposes, as mobile devices can help in wayfinding in the new city.

The contribution of this paper is threefold: first, it adds to the literature of students' mobility by examining their travel preferences and behavior; second, it increases our understanding of travel behavior adaptation by analyzing the factors influencing individuals' perception, behavior, and satisfaction with public transport following an international relocation; and third, it enhances our understanding on how previous habits and experiences can shape/influence individual behavior.

This paper is structured as follows. Section 2 presents the literature review on travel behavior changes after relocation and the effect of habits, availability of transport modes, and technology on those changes. Section 3 discusses the hypotheses investigated in this study, offers an overview of survey design, gives information on data collection, and describes the model approach used and the reasons underlining its choice. Section 4 describes the results of our model and its associated fit indices and a discussion of obtained results. Section 5 offers reflections about the implications of the results, suggestions for further research, and discusses the limitations of this work.

\section{Literature Review}

As relocation essentially imposes changes in individuals' travel opportunities and constraints, habit break is likely to occur as soon as the need to deliberate on how to move around arises and individuals face the chance of re-evaluating their transport choices. In line with the literature on behavioral change, after relocation, a "window of opportunity" is created, as individuals confront a new environmental context that makes them re-evaluate their choices and, consequently, weakens their habits [20-22]. The new context presents a new set of information, making individuals stop doing things in an automatic way [23].

However, [24] argues that residues of past behavior resulting from previous habits influence attitudes and the perceived self-efficacy in a new place (for our study, regarding the transport options available). Moreover, empirical evidence links previous exposure to high-quality public transport with higher public transport use [25]. In this regard, past habits and experiences can contribute to expectations regarding the use of different transport options in the host city, making international students and researchers more inclined to use transport options similar to those used in their previous city of residence. In other words, even though relocation makes people re-evaluate their choices, they are likely to do it in line with previous exposure to the different transport modes.

Another constraint arises to find a similar solution for traveling in the host city: the smaller choice set resulting from the temporary transnational relocation, as private vehicles are not brought from the city of origin. About adaptation, Cao and Moktarian [26] point out 
that individuals prefer to adopt lower-impact strategies (e.g., changing departure times) to adapt to a new situation before adopting higher-impact ones (e.g., telecommuting). Thus, their low likelihood to invest in a private individual mode for a short-term horizon results in a higher likelihood of international students and researchers' reliance on public transport and/or non-motorized modes in the host city [16,19].

Consequently, for those who were not users of Public Transport (PT) in the past city and are potentially more resistant to PT use, this may result in a choice of residential location that minimizes the need of using PT in the host city. In this sense, the relationship between the choices of residential location and transport mode is highlighted, and a compromise between the preferences associated with these choices tends to happen [27]. Different from other relocation scenarios, the temporary residents have no long-term commitment to the location chosen and are staying in the host city to develop mandatory activities in a previously known location (e.g., university, research center). The lack of long-term commitment may make them more flexible in their decision-making, while prior knowledge about the location of the presumed most frequent destination configures an advantage or opportunity to be explored. This prior information on study/workplace location allows for the consideration of commuting distance/mode during the residential location decision-making. The literature reveals that even after quite a few empirical investigations, there is no consensus on the direction of causality between mode choice and residential preferences $[11,28-30]$, and some authors claim that even when the residential choice is influenced by transport preferences (self-selection), there are also influences in the opposite direction $[8,31]$. The latter impact occurs due to the features of the built environment, as, for example, higher connectivity and accessibility of PT services are known to increase its attractiveness and levels of use [32].

The lack of information and familiarity with the available transport modes also impacts the travel behavior of international students and researchers, resulting in more constraints associated with the travel behavior. Using a new transport mode requires learning the new routines associated with it [33], and when the efforts related to this process are perceived to exceed its benefits, one can end up using a less optimal transport mode that is easier to use. Therefore, for international students and researchers to start using and relying on PT, it is essential to make it easy to use by newcomers, as perceiving PT as not easy to use can discourage its use [34]. Note that when the public transport system is designed to meet the needs of those who are unfamiliar with the spatial and transportation characteristics of a city (newcomers), public transport will be easy to use by any other user [35]. Thus, experiences about the perceived easiness of using PT can update the perceptions, attitudes, and preferences associated with different transport modes, despite the role of prior attitudes and predispositions [33]. After experiencing the mobility options in the host city, people can change their attitudes towards PT. For example, when individuals move to a location with a different level of access to public transport, the experience of traveling by public transport in the new area may influence their attitudes [30].

With this in mind, the use of technology to deliver information offers an opportunity to overcome this barrier more easily since temporary residents are usually young adults who have the flexibility to move abroad [36]. Therefore, international students and researchers are likely to be Millennials who are characterized by intensive use of technology, which impacts several aspects of their daily lives. The use of technology for transport purposes enhances the possibilities for traveling, which allows for travel optimization, high-level information possibilities, freedom, and flexibility [37]. In this sense, delivering a mobility tool perceived as useful for moving around in the host city can contribute to an easier adaptation.

Existing studies on satisfaction with public transport draw attention to the influence of safety, service frequency, reliability, travel information at stops, ease of transfers [38], perceived costs [39], and frequency of public transport use [40]. Moreover, as residential location plays a role in defining both commuting distance and accessibility, it is reasonable 
to say that this may affect public transport satisfaction. Both high accessibility [39] and shorter commuting distances are associated with higher satisfaction levels [40].

\section{Hypotheses, Data, and Methods}

\subsection{Hypotheses}

Based on the literature review, we decided to explore and test the following hypotheses:

Hypothesis 1 (H1). Previous travel habit is associated with the past frequency of Public Transport (PT) use and influences residential location choice (self-selection) [27,31,41];

Hypothesis 2 (H2). Past frequency of PT use affects the current frequency of PT use and the initial perception about the easiness to use PT in the new city [24,25];

Hypothesis 3 (H3). Residential location (which defines accessibility level) influences the current frequency of PT use [32] and satisfaction with PT [39];

Hypothesis 4 (H4). Perception of technology as a tool to help in mobility is positively related to the initial perception about the easiness to use PT [37];

Hypothesis $\mathbf{5}$ (H5). The initial perception about the easiness to use PT is positively related to the current frequency of PT use and the satisfaction with PT [34];

Hypothesis 6 (H6). PT frequency of use is positively related to satisfaction with PT [40].

Figure 1 summarizes the above hypotheses that will be tested and aid the model development.

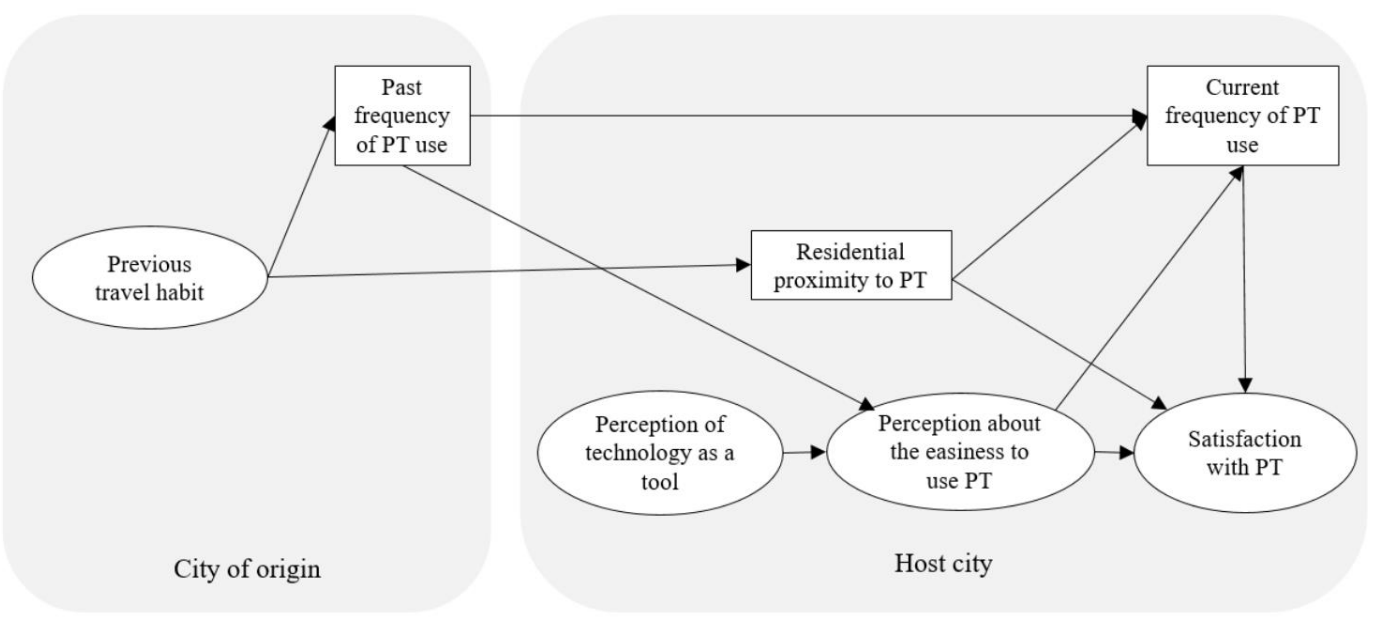

Figure 1. Theoretical framework with hypothetical relationships to be tested.

\subsection{Survey Design and Data Collection}

An online survey was designed and implemented for international students and researchers at the University of Porto. As international students may have some budgetary restrictions that make them deviate from other temporary residents' subgroups, we will discuss in the Section 5 what can potentially be generalized for other segments of temporary residents. The questionnaire design was based on a literature review and on in-depth interviews previously made with international students from 9 different countries who were living in Porto or Lisbon (Portugal) during January 2018 [42]. Since our focus was to accurately capture behavior adaptation and the impact of initial perceptions and early choices on behavior adaptation, only students and researchers who were either in a short exchange or in their first year of a full degree in Portugal were considered eligible. The 
web-based survey, implemented between May and June of 2018, was distributed by the University of Porto International Office through an email inviting all eligible international students and researchers to answer. Although participation in the survey required internet access and digital literacy skills, we did not anticipate any sample bias in a population that is young, well-educated, and has free access to both computers and the internet at the university.

The survey questions covered sociodemographic characteristics, past frequency of PT use, past habits, current residential location, the current frequency of PT use, initial easiness in using the PT system, technology usage for mobility purposes, and satisfaction with PT. Sociodemographic characteristics focused on gender, age, country of origin, driver's license ownership, role at the university, time living in the host city, and criteria for residential choice in the host city.

Past frequency of PT use was measured by the perceived frequency of PT use in the city of origin, disregarding trip purpose. The past habit was measured through the adaptation of the Self-Report Habit Index (SRHI) proposed by Verplanken and Orbell [43]. Our purpose was to measure the existence of habit, i.e., lack of deliberation, related to mode choice in the city of origin. Therefore, we decided to control for past habits regarding mode choice because: (i) the residential location choice can be influenced by previous transport mode choices (in the respondents' city of origin), and (ii) those who mostly use public transport in the city of origin are more likely to seek it in the host city.

Residential location self-selection was examined through the variable Residential Proximity to Metro (RPM), which was a binary variable constructed by combining the stated current residential location with information on metro stations' location retrieved from Google Maps. The RPM considered whether the closest metro was reachable in a radius of $500 \mathrm{~m}$ from the residence of each respondent, which characterizes high accessibility to rail and could highlight self-selection occurrence [44]. We decided to use this measure for public transport access because the network of buses is quite homogeneous inside Porto. The current frequency of PT use was measured by the perceived frequency of PT use in the host city, disregarding trip purpose. Initial easiness in using the PT was measured by combining the perceived easiness-of-use metro and bus. The perception of technology as a tool to facilitate mobility in the host city was elicited in terms of its use for enhancing wayfinding, trip planning, optimization, and adaptation to the host city transport system. The satisfaction with PT was measured regarding the evaluation of travel and waiting times, information services, coverage, and cancellations/delays.

The questions associated with these items were graded in a 5-point Likert scale from "strongly disagree" to "strongly agree", except the ones related to initial easiness in using PT system that were graded in a 5-point Likert scale from "very difficult" to "very easy". The questionnaire was provided in English and Portuguese and took about 15 min to complete.

\subsection{Bayesian Structural Equation Model}

Structural Equations Modeling was the method chosen because it provides a way to combine unobserved (individuals' perception, satisfaction) and observed (individual's behavior) variables, allowing for testing the relationships between them [45]. As the questionnaire included positive and negative worded sentences, we have reversed the scores before data analysis. An exploratory factor analysis was performed, resulting in the identification of four factors that we tested for sample adequacy (Kaiser-Meyer-Okin measure-KMO) [46] and internal consistency (Cronbach's alpha) [47]. KMO values can vary between 0 and 1, where values close to zero indicate dispersion in the pattern of correlations, meaning that the factor analysis is likely to be inappropriate and values close to 1 indicate that patterns of correlations are relatively dense and so factor analysis should yield different and reliable factors [46]. For Cronbach's alpha, values of 0.9 and above show excellent reliability, values between 0.7 and 0.9 show high reliability, values between 0.5 and 0.7 show moderate reliability, and values of 0.5 or below show low reliability [48]. 
Based on the results, a Structural Equations Model (SEM) was implemented in Mplus [49]. Given the sample size, we proceeded with Bayesian estimation (BSEM) because it performs better for small samples [50]. SEM consists of a measurement model, or confirmatory factor analysis model, to examine the relationships between observed variables and latent variables. In this study, the model consisted of 4 sets of equations. Equation (1) refers to the measurement equations, Equation (2) connects the latent variables to individual's socioeconomic characteristics, Equation (3) links the explanatory and the mediator latent variables, and Equation (4) connects the latent mediators to the dependent variable:

$$
\begin{gathered}
\mathrm{I}_{r n}=\mathrm{Z}_{l n}^{*} \alpha_{r}+v_{r n} \text { and } v_{n} \sim \mathrm{N}\left(0, \Sigma_{v}\right) \text { for } r=1, \ldots, R \\
\mathrm{Z}_{l n}^{*}=\mathrm{S}_{l n} \beta_{l}+\omega_{l n} \text { and } \omega_{n} \sim \mathrm{N}\left(0, \Sigma_{\omega}\right) \text { for } l=1, \ldots, L \\
\mathrm{Z}_{l}^{*}=\mathrm{Z}_{i} \beta_{i}+\varphi_{l} \text { and } \varphi_{l} \sim \mathrm{N}\left(0, \Sigma_{\varphi}\right) \text { for } l=1, \ldots, L \& i=1, \ldots, I \\
\mathrm{Y}_{i n}=\mathrm{Z}_{l n}^{*} \gamma_{\mathrm{Z}}+\xi_{n} \text { and } \xi_{n} \sim \mathrm{N}\left(0, \Sigma_{\xi}\right) \text { for } i=1, \ldots, I
\end{gathered}
$$

where $\mathrm{I}_{r n}$ is a vector of indicators $r$ of the latent constructs as perceived by individuals $n, \alpha_{r}$ is a matrix of factor loadings and $v_{r n}$ is a random vector of measurement (residual) errors which follow a normal distribution with covariance matrix $\Sigma_{v}, Z_{l n}^{*}$ is a vector containing the latent variables, $S_{l n}$ is a vector of individuals' socioeconomic characteristics, $Z_{l}^{*}$ refers to the mediator latent construct, and $Z_{i}$ refers to the explanatory latent construct. $\beta_{l}$ and $\beta_{i}$ contain parameters that reflect directed paths between sociodemographic variables and latent variables and among exploratory and mediator latent variables, respectively. $\omega_{l n}$ and $\varphi_{l}$ are error term vectors, which follow a normal distribution with respective covariance matrix $\Sigma_{\omega}$ and $\Sigma_{\varphi} . Y_{i n}$ is the dependent variable, $\gamma_{z}$ is the parameter that represents the regression relations between the latent variables and the dependent variable, and $\xi_{n}$ is a vector of error terms which follow a normal distribution with covariance matrix $\Sigma_{\xi}$.

We chose to apply the BSEM approach described in Muthén and Asparouhov [50] that consists of methodically set small-variance informative priors in the measurement model for cross-loadings and residual correlations that should rather be constrained to be close to zero than set to zero or freely estimated. This adjustment in the measurement model the theory under study through the SEM to be better reflected [50]. After a sensitivity analysis, we chose $\mathrm{N}(0,0.02)$ as informative priors for the cross-loadings, corresponding to priors with means equal to zero and variances of 0.02 , so that $95 \%$ of the loading variation limit was between -0.28 and +0.28 . As informative priors for the residual covariances among factor indicators, we defined an inverse-Wishart distribution-IW $(0,500)$, where the zeros are used to form the covariance matrix and 500 represents the degrees of freedom (the higher the degrees of freedom, the smaller the variances of the priors). The goodnessof-fit of the model was assessed by the Posterior Predictive $p$-value (PPP). A PPP value above 0.05 indicates an acceptable fit, being a PPP value of around 0.5 an indication of an excellent-fitting model [50].

\subsection{Sample Characteristics}

The survey provided 298 complete responses in total, and the sample characteristics are presented in Table 1 . The majority of the respondents were women, aged between 18 and 25 years old, with a driver's license, from the Americas (mostly Brazil), bachelor students, that chose their residence before moving to Porto.

An initial analysis of the data showed a significant decrease in car usage and an increase in PT use and walking (see Figure 2). In total, 37.9\% of the respondents reported an overall increase in PT use, and 50.5\% increased their frequency of walking. It is worth mentioning that this significant increase in walking can be associated with contextual factors, as potential bicycle users may decide not to use this mode in Porto due to specific elements, such as topography (hilly), the lack of continuous bike lanes, and the inexistence of a public bike-sharing system. 
Table 1. Sample characteristics.

\begin{tabular}{|c|c|c|}
\hline Variables & Total & $\%$ \\
\hline Gender $(1=$ man $)$ & 130 & 43.62 \\
\hline \multicolumn{3}{|l|}{ Age } \\
\hline Between $18-25$ years & 183 & 61.41 \\
\hline Between 26-30 years & 67 & 22.48 \\
\hline Between $31-40$ years & 40 & 13.42 \\
\hline More than 40 years & 8 & 2.68 \\
\hline Driver's license ( 1 = have DL) & 223 & 74.83 \\
\hline \multicolumn{3}{|l|}{ Continent of nationality } \\
\hline Africa & 10 & 3.36 \\
\hline America & 181 & 60.74 \\
\hline Asia & 22 & 7.38 \\
\hline Europe & 85 & 28.52 \\
\hline Oceania & 0 & 0.00 \\
\hline \multicolumn{3}{|l|}{ Role at the University } \\
\hline Bachelor student & 93 & 31.21 \\
\hline Master student & 69 & 23.15 \\
\hline Integrated master student & 63 & 21.14 \\
\hline PhD student & 52 & 17.45 \\
\hline Post-doc & 5 & 1.68 \\
\hline Researcher & 10 & 3.36 \\
\hline \multicolumn{3}{|c|}{ Moment when respondents have searched for their residence in Porto } \\
\hline Before moving to Porto & 173 & 58.05 \\
\hline After have moved to Porto & 115 & 38.59 \\
\hline $\begin{array}{l}\text { Have not chosen (moved to } \\
\text { live with family or friends) }\end{array}$ & 10 & 3.36 \\
\hline
\end{tabular}

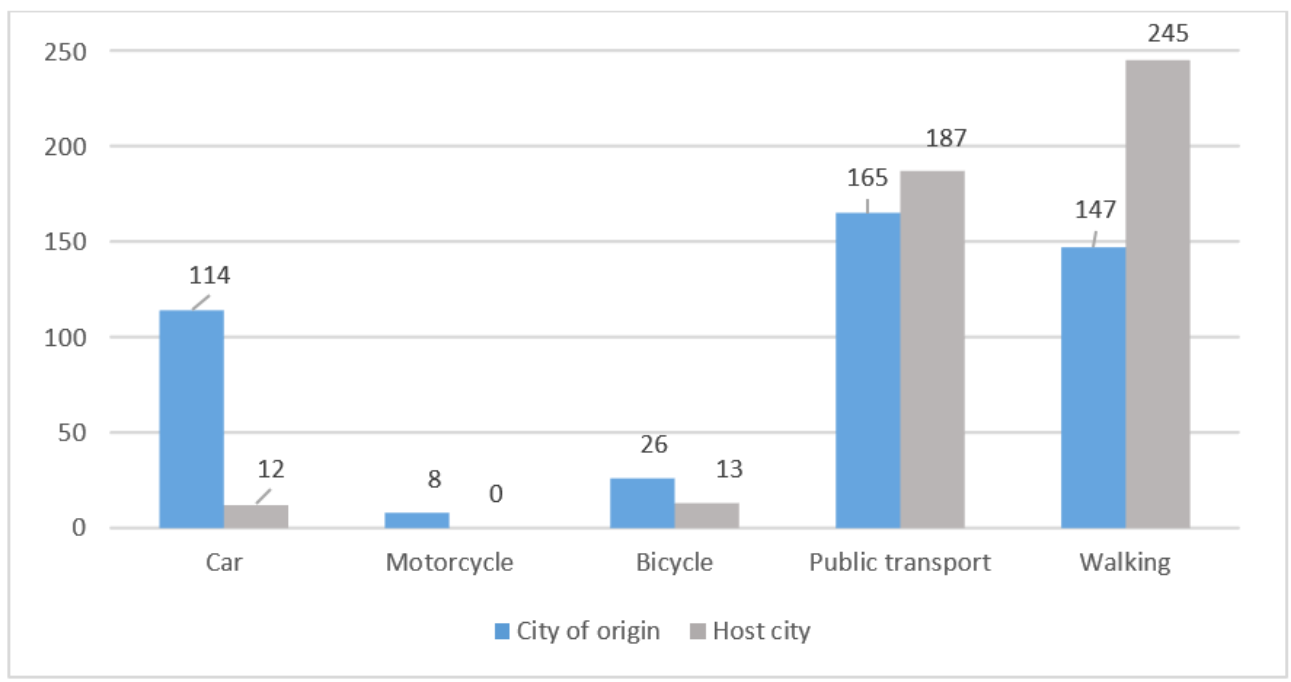

Figure 2. Most frequent mode used in the city of origin and in the host city. 


\section{Results and Discussion \\ 4.1. Exploratory Factor Analysis}

The analysis of the KMO value obtained for the factors associated with habits, perceptions, and satisfaction (graded in a 5-point Likert scale) indicated good sampling adequacy $(\mathrm{KMO}=0.744)$, and the result of Bartlett's test of sphericity allowed us to reject the null hypothesis that the correlation matrix is an identity matrix $(p=0.000)$. Principal axis factoring with varimax rotation (Kaiser normalization) was used and resulted in four factors (see Table 2). The dominant items (marked in bold) were defined considering a cut-off value of 0.5 . The Cronbach alpha values of each factor are presented inside parentheses and indicate moderate to good internal consistency [48]. Please note some items had their coding reserved (marked with $(\mathrm{R})$ ) to made factor interpretation easier for readers.

Table 2. Exploratory factor analysis results.

\begin{tabular}{|c|c|c|c|c|}
\hline Factor (Cronbach Alpha) & $\begin{array}{l}\text { Previous Travel } \\
\text { Habit }(0.663)\end{array}$ & $\begin{array}{c}\text { Perception about the } \\
\text { Easiness to Use PT } \\
(0.526)\end{array}$ & $\begin{array}{l}\text { Satisfaction with } \\
\text { PT (0.696) }\end{array}$ & $\begin{array}{c}\text { Perception of } \\
\text { Technology as a Tool } \\
\text { to Aid Mobility } \\
(0.829)\end{array}$ \\
\hline $\begin{array}{l}\text { I always made my transport choices in an } \\
\text { automatic way }\end{array}$ & 0.604 & 0.007 & -0.049 & 0.128 \\
\hline $\begin{array}{l}\text { Every day I thought very carefully about my } \\
\text { transport choices }(R)\end{array}$ & 0.692 & -0.001 & 0.029 & -0.033 \\
\hline $\begin{array}{l}\text { My daily routine was fixed, so I didn't need to } \\
\text { think about my transport options }\end{array}$ & 0.593 & -0.016 & 0.051 & 0.094 \\
\hline Bus easiness-of-use & 0.050 & 0.643 & 0.104 & 0.027 \\
\hline Metro easiness-of-use & -0.046 & 0.537 & 0.092 & 0.055 \\
\hline Travel and waiting times are too long $(R)$ & 0.014 & 0.091 & 0.667 & 0.068 \\
\hline There are good information services & -0.038 & 0.358 & 0.528 & 0.147 \\
\hline Public transport services cover well all the city & -0.001 & 0.091 & 0.508 & 0.060 \\
\hline There often are service cancellations/delays (R) & 0.046 & -0.020 & 0.673 & -0.050 \\
\hline Optimizes my overall travel experiences & 0.016 & -0.007 & 0.030 & 0.754 \\
\hline Allows me to easily plan my travels & 0.037 & 0.061 & 0.040 & 0.763 \\
\hline $\begin{array}{l}\text { Allows me to find my way in the city and I do } \\
\text { not need anything more to move around }\end{array}$ & 0.121 & 0.035 & 0.044 & 0.702 \\
\hline Allows me to adapt easily to the city's mobility & 0.091 & 0.098 & 0.087 & 0.721 \\
\hline
\end{tabular}

(R) indicates reserved coding of negatively worded items, The dominant items are marked in bold.

The four emergent factors were previous travel habits, perception about the easiness to use PT, satisfaction with PT, and perception of technology as a tool to aid mobility. Previous travel habit is the only construct related to the city of origin. High values on this factor represent a lack of deliberation regarding transport choices. Perception about the easiness to use PT reveals the first impressions about bus and metro use in the host city. Satisfaction with PT exposes the evaluation of different features related to its use. Further, the perception of technology as a tool to aid mobility underlies the respondents perceptions about opportunities and experiences associated with the use of web-based tools and smartphone applications.

\subsection{Measurement Model}

The measurement model consisted of a confirmatory factor analysis (CFA) that tests the fit of the data and validates the factor model construction. As we used the BSEM approach, beyond the loadings in each factor, the estimates for the measurement equations included small-cross loadings, resulting in a structure similar to EFA output (See Table 3). Despite the similarity, the model is guided, and the cross-loadings are restricted by the priors to be small [50]. The factor loadings marked in bold are those for which the $95 \%$ 
credibility interval did not contain zero, thus revealing the structure defined for the factors in the confirmatory analysis.

Table 3. Confirmatory factor analysis results.

\begin{tabular}{|c|c|c|c|c|}
\hline $\begin{array}{c}\text { Factors } \\
\text { Items }\end{array}$ & $\begin{array}{c}\text { Previous Travel } \\
\text { Habit }\end{array}$ & $\begin{array}{l}\text { Perception about the } \\
\text { Easiness to Use PT }\end{array}$ & $\begin{array}{l}\text { Satisfaction } \\
\text { with PT }\end{array}$ & $\begin{array}{c}\text { Perception of } \\
\text { Technology as a Tool }\end{array}$ \\
\hline $\begin{array}{l}\text { I always made my transport choices in an } \\
\text { automatic way }\end{array}$ & 0.591 & 0.006 & -0.044 & 0.110 \\
\hline $\begin{array}{l}\text { Every day I thought very carefully about } \\
\text { my transport choices (R) }\end{array}$ & 0.791 & -0.001 & 0.010 & -0.071 \\
\hline $\begin{array}{l}\text { My daily routine was fixed, so I didn't } \\
\text { need to think about my transport options }\end{array}$ & 0.653 & -0.001 & 0.013 & 0.065 \\
\hline Bus easiness-of-use & 0.063 & 0.538 & 0.073 & -0.015 \\
\hline Metro easiness-of-use & -0.016 & 0.866 & -0.017 & -0.012 \\
\hline Travel and waiting times are too long (R) & 0.008 & 0.001 & 0.645 & 0.021 \\
\hline There are good information services & -0.036 & 0.091 & 0.620 & 0.095 \\
\hline $\begin{array}{l}\text { Public transport services cover well all } \\
\text { the city }\end{array}$ & -0.013 & -0.015 & 0.596 & 0.011 \\
\hline $\begin{array}{l}\text { There often are service } \\
\text { cancellations/delays (R) }\end{array}$ & 0.040 & -0.063 & 0.702 & -0.108 \\
\hline Optimizes my overall travel experiences & -0.005 & -0.035 & -0.014 & 0.824 \\
\hline Allows me to easily plan my travels & -0.012 & 0.003 & -0.009 & 0.879 \\
\hline $\begin{array}{l}\text { Allows me to find my way in the city and } \\
\text { I do not need anything more to } \\
\text { move around }\end{array}$ & 0.035 & -0.001 & -0.010 & 0.795 \\
\hline $\begin{array}{l}\text { Allows me to adapt easily to the } \\
\text { city's mobility }\end{array}$ & 0.001 & 0.022 & 0.029 & 0.831 \\
\hline
\end{tabular}

(R) indicates reserved coding of negatively worded items, The dominant items are marked in bold.

The Posterior Predictive $p$-Value (PPP) was 0.554, indicating an excellent fit of the results of confirmatory factor analysis. A PPP value above 0.05 indicates an acceptable fit, and a PPP value around 0.5 indicates an excellent fitting model [50].

The factors are the same as presented in the previous subsections, but here their structure is fixed (previously determined) with small cross-loadings and residual correlations being allowed.

\subsection{Structural Equations Model}

Tables 4 and 5 present the relationship between the latent constructs and respondents' characteristics and the relationship between the latent constructs (with respondents' characteristics already associated) and PT frequency of use and satisfaction with PT, respectively. The PPP-Value of the structural model was 0.361, indicating a good fit [50].

Table 4. Estimates of SEM relating respondents' characteristics and latent constructs.

\begin{tabular}{|c|c|c|c|c|c|c|}
\hline & \multirow{2}{*}{ Estimate } & \multirow{2}{*}{ Posterior S.D. } & \multicolumn{2}{|c|}{ 95\% C.I. } & \multicolumn{2}{|c|}{$90 \%$ C.I. } \\
\hline & & & Lower $2.5 \%$ & Upper $2.5 \%$ & Lower 5\% & Upper $5 \%$ \\
\hline \multicolumn{7}{|c|}{ Perception about the easiness to use PT } \\
\hline Integrated master student & 0.197 & 0.067 & 0.065 & 0.323 & & \\
\hline Ph.D. student & 0.154 & 0.068 & 0.018 & 0.285 & & \\
\hline $\begin{array}{c}\text { Come from a } \\
\text { European country }\end{array}$ & -0.197 & 0.073 & -0.337 & -0.051 & & \\
\hline
\end{tabular}


Table 4. Cont.

\begin{tabular}{|c|c|c|c|c|c|c|}
\hline & \multirow{2}{*}{ Estimate } & \multirow{2}{*}{ Posterior S.D. } & \multicolumn{2}{|c|}{ 95\% C.I. } & \multicolumn{2}{|c|}{ 90\% C.I. } \\
\hline & & & Lower $2.5 \%$ & Upper $2.5 \%$ & Lower $5 \%$ & Upper $5 \%$ \\
\hline \multicolumn{7}{|c|}{ Satisfaction with PT } \\
\hline Post-doc student & -0.171 & 0.059 & -0.284 & -0.052 & & \\
\hline $\begin{array}{l}\text { Come from a } \\
\text { European country }\end{array}$ & -0.134 & 0.068 & -0.266 & 0.000 & -0.246 & -0.021 \\
\hline $\begin{array}{l}\text { Had chosen the current } \\
\text { residential place }\end{array}$ & 0.218 & 0.065 & 0.075 & 0.325 & & \\
\hline $\begin{array}{l}\text { Live in Porto for more than } \\
6 \text { months }\end{array}$ & -0.297 & 0.057 & -0.407 & -0.183 & & \\
\hline \multicolumn{7}{|c|}{ Perception of technology as a tool } \\
\hline Ph.D. student & -0.199 & 0.059 & -0.308 & -0.079 & & \\
\hline $\begin{array}{c}\text { Come from a } \\
\text { European country }\end{array}$ & -0.221 & 0.061 & -0.332 & -0.096 & & \\
\hline
\end{tabular}

C.I. stands for credibility interval. Bold indicates that the credibility interval does not contain zero. The dominant items are marked in bold.

Table 5. Estimates of structural equations relating latent constructs to PT frequency of use and satisfaction.

\begin{tabular}{|c|c|c|c|c|c|c|}
\hline & \multirow{2}{*}{ Estimate } & \multirow{2}{*}{ Posterior S.D. } & \multicolumn{2}{|c|}{ 95\% C.I. } & \multicolumn{2}{|c|}{ 90\% C.I. } \\
\hline & & & Lower $2.5 \%$ & Upper $2.5 \%$ & Lower 5\% & Upper $5 \%$ \\
\hline \multicolumn{7}{|c|}{ Past frequency of PT use } \\
\hline Previous travel habit & -0.225 & 0.073 & -0.364 & -0.080 & & \\
\hline \multicolumn{7}{|c|}{ Residential proximity to metro } \\
\hline Previous travel habit & -0.118 & 0.070 & -0.256 & 0.016 & -0.233 & -0.004 \\
\hline \multicolumn{7}{|c|}{ Perception about the easiness to use PT } \\
\hline $\begin{array}{l}\text { Perception of technology as } \\
\text { a tool }\end{array}$ & 0.248 & 0.128 & -0.028 & 0.483 & 0.025 & 0.447 \\
\hline \multicolumn{7}{|c|}{ Current frequency of PT use } \\
\hline Past frequency of PT use & 0.283 & 0.063 & 0.155 & 0.400 & & \\
\hline Residential proximity to metro & 0.150 & 0.061 & 0.033 & 0.268 & & \\
\hline $\begin{array}{l}\text { Perception about the easiness } \\
\text { to use PT }\end{array}$ & 0.384 & 0.074 & 0.238 & 0.527 & & \\
\hline \multicolumn{7}{|c|}{ Satisfaction with PT } \\
\hline $\begin{array}{l}\text { Perception about the easiness } \\
\text { to use PT }\end{array}$ & 0.334 & 0.149 & 0.025 & 0.606 & & \\
\hline Residential proximity to metro & 0.118 & 0.063 & -0.003 & 0.242 & 0.016 & 0.222 \\
\hline Current frequency of PT use & -0.237 & 0.080 & -0.395 & -0.078 & & \\
\hline
\end{tabular}

C.I. stands for credibility interval. Bold indicates that the credibility interval does not contain zero.

The sociodemographic variables tested were gender, age, country of origin, driver's license ownership, role at the university, time living in the host city, and criteria for residential choice in the host city. However, the model only included those socioeconomic variables that presented a statistically significant relationship with the latent variables. The latent construct habit was not significantly influenced by any of the sociodemographic characteristics tested.

Regarding the relationship with sociodemographic characteristics, individuals who came from other European countries tended to perceive the PT as more challenging to use, to perceive the technology as not much helpful for moving around, and to feel less satisfied 
with the PT. For them, it is likely that language barriers (not encountered by individuals from Brazil, for example), lack of efficient tools to help in moving around, and experiencing a PT system with lower levels of service than in their country of origin, especially for those who moved from northern countries, contributed to the low satisfaction.

Similarly, Ph.D. students tended to perceive technology as not much help, but they perceived the PT system as easier to use. Integrated master students were also found to perceive the PT as easier to use. Additionally, post-doctoral researchers and respondents living in Porto for more than six months were less satisfied with the PT system. For the latter, more exposure to the system's problems is a possible explanation.

In contrast, those who chose their residential place were more satisfied with the PT system. To clarify, some of the respondents did not choose their residential location, mainly because they moved to live with friends or family who were already living in Porto (see Table 1). In this sense, the lack of residential location choice seemed to reduce satisfaction with the PT system.

As for the relationships between the variables and factors, Table 5 and Figure 3 present the significant relationships found (the solid and dashed lines indicate positive and negative relationships, respectively).

As expected, the model structure confirmed H1, meaning that the existence of a previous travel habit is associated with the frequency of PT use in the previous city and residential location choice in the host city. The frequency of PT use was negatively related to previous travel habits because this factor was actually positively related to the frequency of car use and negatively associated with the use of public transport, bike, walking, carsharing and ride hailing, taxi, or similar. Table 6 shows that a higher frequency of car use was associated with a higher level of travel habit in the city of origin and, thus, to a lower level of deliberation on mode choice. Conversely, higher use of public transport, bicycle, car-sharing, and walking, was associated with lower levels of travel habit, suggesting a higher level of deliberation. As habit is a psychological construct rather than a simple reflection of past behavioral frequency [43], it could be that despite frequency, the use of PT and other travel options do not present a stable context or are not as rewarding (other conditions for habit formation pointed out by Oullette and Wood [51]) as car use. Regarding the former, for example, frequent public transport users may still need to think about and choose between different PT modes (e.g., bus, metro), route, transfers, and schedule options. Thus, the existence of travel habits in the city of origin was negatively associated with the past frequency of PT use and decreased the likelihood of choosing to live close to a metro station in the host city. This revealed that frequent users of public transport in the city of origin tended to choose to live in locations that have good public transport connections, as they might have a higher preference for this mobility solution. This evidences the occurrence of self-selection, i.e., individuals' mobility preferences influence residential location choice.

Table 6. Spearman's correlation between habit construct and use frequency of modes in the city of origin.

\begin{tabular}{ccc}
\hline & \multicolumn{2}{c}{ Travel Habit } \\
\hline Frequency of Use & $\begin{array}{c}\text { Correlation } \\
\text { Coefficient }\end{array}$ & Sig. (2-Tailed) \\
\hline Car (as driver or as passenger) & $0.151^{* *}$ & 0.009 \\
\hline Public transport & $-0.198^{* *}$ & 0.001 \\
\hline Bicycle & $-0.160^{* *}$ & 0.006 \\
\hline Car-sharing & $-0.155^{* *}$ & 0.007 \\
\hline $\begin{array}{c}\text { Walking (as the main mode, } \\
\text { not as access to other modes) }\end{array}$ & $-0.206^{* *}$ & 0.000 \\
\hline Correlation is significant at the 0.01 level (2-tailed). &
\end{tabular}




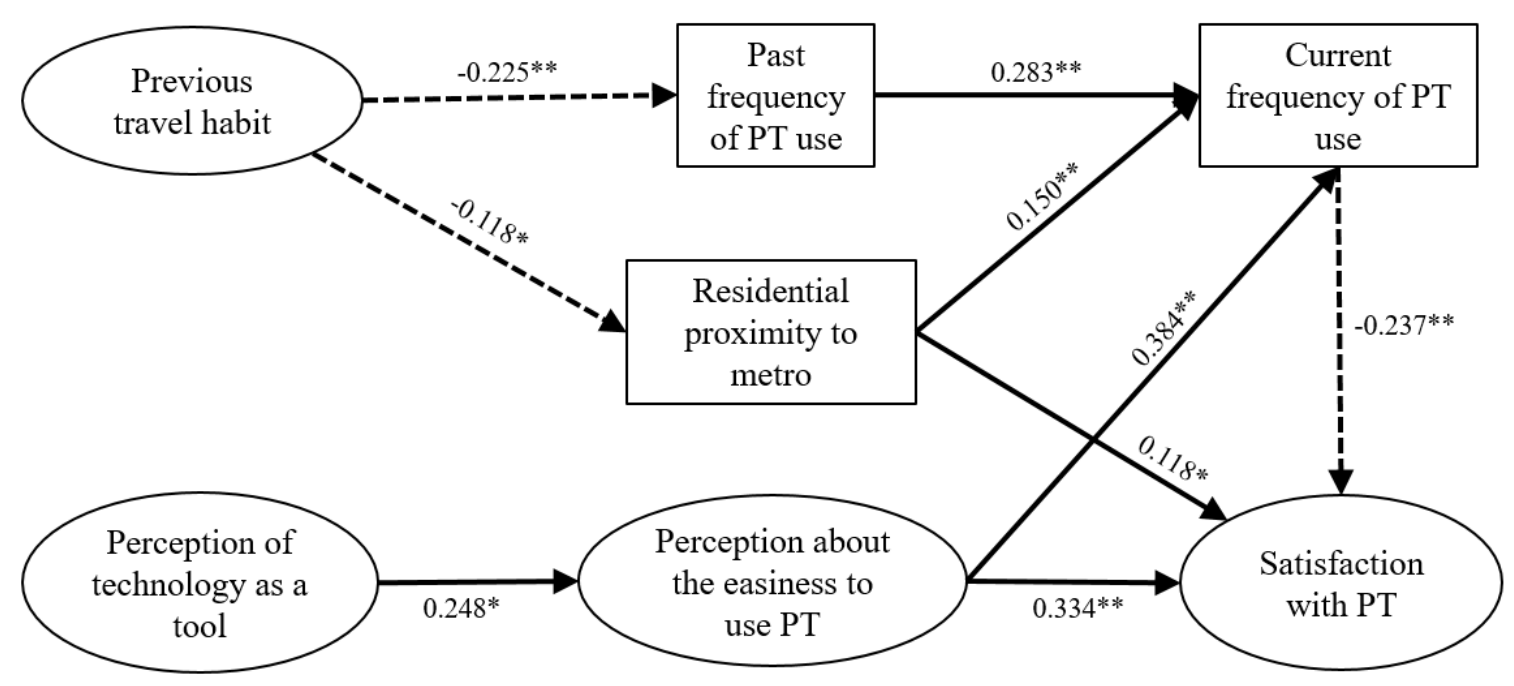

Figure 3. Model structure relating PT frequency of use and satisfaction with PT to the latent constructs. ${ }^{* *}$ indicates $95 \%$ credibility interval; * indicates $90 \%$ credibility interval.

As for H2, the model only partially confirmed it, since the higher the frequency of PT use in the city of origin, the higher the use of PT in the host city, but no significant relationship between past frequency of use in the city of origin and perception about the easiness to use PT was found. These results suggest that previous experience with public transport increases the likelihood of using public transport in the host city. However, this did not seem to happen because individuals who were more familiar with public transport systems (frequent users) found it easier to understand the public transport system in the host city. Rather, the perceived ease-of-use of the local public transport system seemed to depend on the characteristics of the system itself and its level of information provision.

The model endorsed H3, which states that the residential location choice affects the current frequency of PT use and satisfaction, as the results indicated that living close to a metro station leads to higher values of PT use frequency and satisfaction. As supported by the results related to $\mathrm{H} 1$, individuals may choose to locate themselves close to places with good public transport accessibility because they intended to rely on them. This is then translated into higher levels of public transport usage. However, as discussed in Section 2, it may also be the case that better public transport accessibility close to the residence makes individuals more prone to use it. As for the connection between high accessibility to metro stations and public transport satisfaction, this finding is supported by previous studies that identified a tendency of higher satisfaction levels among metro users compared to bus users [52]. H4 was confirmed by the model as perceiving technology as helpful to move around makes individuals recognize the PT system as easier to use at the beginning of their stay (the moment when an individual has less knowledge about the system). It is worth mentioning that international students and researchers are part of a young, highly skilled population that is more likely to rely on technology, and thus, this source of information tends to be particularly relevant to them. The model also supported H5, i.e., that perceiving the PT as easier to use leads to a higher frequency of its use and also to higher satisfaction with the PT system. This is an important finding for transport operators, as it suggests that providing clear and easy to access information may lead not only to higher levels of public transport use but also higher levels of satisfaction. Combining these findings, it is evident that good provision of online information leads to a positive impact on public transport ridership and satisfaction for international students and researchers.

Finally, contrary to our initial expectations, the higher the frequency of PT use, the lower the satisfaction with PT, thus H6 is rejected. Although the frequency of public transport usage as a whole was associated with a lower satisfaction level, those living close to a metro station were more associated with higher satisfaction levels with public transport. This suggests that lower satisfaction levels were associated with a high frequency 
of bus usage. This finding is consistent with [39], who found that younger passengers and students tend to be less satisfied with public transport despite using it more frequently than other age groups. Other possible explanations of the underlying causes of this negative association include user captivity $[38,53,54]$, higher exposure to problems in the system [55], and/or residential location dissonance since those who were not able to choose their residence in the host city (relocated to live with friends or relatives) presented relatively lower levels of satisfaction with PT.

\section{Conclusions}

This study addressed the travel behavior adaptation of young temporary residents in the context of a transnational relocation. The empirical evidence revealed that international students and researchers tended to change their prior travel behavior replacing individual private transport with public transport alternatives and/or walking. Moreover, the obtained results suggested that PT frequency of use in the host city was influenced by usage patterns in the city of origin. However, the initial perception about how easy it is to use public transport has a stronger effect on individuals' frequency of use and associated satisfaction levels. Moreover, the model revealed that the perception of how easy it is to use public transport was not significantly impacted by the level of familiarity with public transport systems (frequent vs. non-frequent PT users in the city of origin), emphasizing the role of transport operators in delivering a user-friendly system.

From a policy perspective, these results highlight an opportunity for increasing ridership in public transport. They show the importance of taking advantage of the sensitive stage at the beginning of temporary residents' stays to nudge them towards the use of the public transport resources that the host city has. In this sense, public transport authorities and operators should work towards reducing the difficulties in using PT felt by people not familiar with the system, as these individuals lack the knowledge about the PT system organization, fare systems, and the spatial connections it provides. Close collaboration with universities for promoting clear and accessible public transport information essential to navigate the system has the potential for increasing ridership and satisfaction for this group. As language can be a barrier for temporary residents, information in English can significantly decrease the cognitive effort necessary to understand the basics about fares and connections between public transport modes. Moreover, improving the overall presentation of information for the general public has the potential to attract other groups that are less familiar with public transport but are reconsidering their transport options or for other types of temporary stays (e.g., tourists).

Additionally, according to our findings, one possibility to boost the easiness of using public transport would be to improve the usability of technology as a mobility support tool. The provision of information about the transport system through technological devices in simple and easy-to-use formats is essential for helping newcomers to have a smoother transition between different cities and countries. In addition, internet browser extensions allow individuals to easily translate webpage and better understand the available information. Another interesting outcome of this research is the relationship between previous travel habits and PT accessibility at the residential location (residential proximity to the metro) that highlights the occurrence of self-selection and, thus, the connection between mode and residential location choices in the host city. For temporary residents, residential location preferences seemed to be affected by intentions towards mode use, in line with the study of Choocharukul et al. [56].

Yet, the fact that good transport accessibility (proximity to metro station) had a positive and independent impact on PT frequency of use indicates that the transport infrastructure can influence transport preferences. The relationship between residential proximity to metro with both satisfaction with PT and current frequency of PT use were evidence of the other direction of influence, as the location is influencing the travel behavior and the satisfaction level. This highlights the role that rail infrastructure could have as the initial reference point for the PT system and is concurrent with the fact that rail-based services 
tend to have higher satisfaction levels [52]. In this sense, self-selection is likely to result in higher levels of satisfaction for those who could choose to live in a more accessible and better-covered location [57]. Related to self-selection, as most people chose their residential location before moving to the host city (see Table 1) and rail-based networks tend to be easier to understand than the bus network, it is likely that under this context of limited information, these individuals' end up favoring proximity to rail-based public transport. Aiming to decrease potential pressures due to high demand for these systems, universities can provide more info on public transport connections before relocation, especially related to relevant bus routes.

It is worth mentioning that as our sample was composed of international students and researchers, budget restrictions and/or lack of choice in regard to where to live is likely to occur for some of them, preventing the possibility of self-selecting despite their desire to do so. Thus, it is possible that the relationship between previous travel habits and residential proximity to the metro is actually stronger than what our findings indicate. Related to that, as the COVID-19 pandemic has impacted international travel negatively, the number of international students and researchers has, at least temporarily, decreased significantly. Because of this decrease in demand, it is likely that students and researchers will face a renting market where the relatively lower competition will favor better self-selection, i.e., those who before needed to opt for living far from the university because of budget constraints may now not face this problem, at least considering a short-term period after the end of the COVID-19 pandemic. Moreover, as, in general, the COVID-19 pandemic has negatively impacted public transport usage [58,59], it may be the case that students and researchers may develop a higher preference for locating themselves closer to the university in order to have the possibility of commuting by active modes. In this sense, our study provides an essential baseline to allow future studies to compare whether and how the residential location and travel behavior preferences of this group have been affected by the COVID-19 pandemic.

The results also suggest the existence of a negative relationship between PT frequency of use and satisfaction with PT. The reason why this occurred is not clear, and further research is needed to investigate it. However, as mentioned before, possible explanations are associated with user captivity, higher exposure to problems in the system, and/or residential location dissonance. A varied range of transport solutions should be offered in the host city to mitigate potential PT captivity problems, so those staying for a short-term period can actually choose how they want to move around. Quality surveys can help in identifying recurrent problems and barriers to use PT and improve its level of service. As for reducing the chances of residential dissonance among international students and researchers, more information about the different neighborhoods of the host city must be timely provided to allow for informed decisions.

Important limitations of this study need to be considered. The small sample size required a Bayesian Estimation for the Structural Equation Model to explore statistically significant relationships, but a bigger sample may help the interpretability of results. Moreover, the data collection was made in a city with a well-developed PT system, but that had not yet implemented emerging shared mobility alternatives (such as electric scooters, bike-sharing systems). Thus, repeating the survey in a city with more mobility possibilities is of interest to verify whether or not people do shift from public transport or walking-based mobility to shared mobility solutions. Further research is also needed to investigate whether social networks in the host city have some influence on an individual's perceptions of easiness and frequency of public transport use.

Author Contributions: Conceptualization, M.M.M. and J.d.A.eS.; methodology, M.M.M. and J.d.A.eS.; software, M.M.M.; validation, M.M.M. and J.d.A.eS.; formal analysis, M.M.M., J.d.A.eS., J.B.I. and O.A.N.; investigation, M.M.M.; resources, J.d.A.eS., J.P.d.S. and O.A.N.; data curation, M.M.M.; writing—original draft preparation, M.M.M.; writing—review and editing, M.M.M., J.d.A.eS., J.B.I. and J.P.d.S.; visualization, M.M.M. and J.B.I.; supervision, J.d.A.eS., J.P.d.S. and O.A.N.; project 
administration, J.d.A.eS.; funding acquisition, J.P.d.S. All authors have read and agreed to the published version of the manuscript.

Funding: The first author is funded by project NORTE-08-5369-FSE-000038, supported by the Northern Portugal Regional Operational Program (NORTE 2020), under the PORTUGAL 2020 Partnership Agreement, through the European Social Fund (ESF).

Institutional Review Board Statement: Not applicable.

Informed Consent Statement: Not applicable.

Data Availability Statement: The data presented in this study are available on request from the corresponding author. The data is not publicly available due to the fact that it contains personal information and cannot be shared openly.

Acknowledgments: The authors would like to thank the University of Porto International Office for their collaboration in the diffusion of the questionnaire developed in this work.

Conflicts of Interest: The authors declare no conflict of interest. The funder had no role in the design of the study, in the collection, analyses, or interpretation of data, in the writing of the manuscript, or in the decision to publish the results.

\section{References}

1. OECD. International Migration Outlook 2019_Chapter 1. Recent Developments in International Migration Movements and Policies; International Migration Outlook; OECD: Paris, France, 2019.

2. UNESCO. Education: Outbound Internationally Mobile Students by Host Region; UNESCO: Paris, France, 2020.

3. European Commission. Erasmus: Facts, Figures \& Trends; European Commission: Brussels, Belgium, 2015; ISBN 978-92-79-52814-9.

4. European Commission. Erasmus + Annual Report 2019; European Commission: Brussels, Belgium, 2019 ; ISBN 9789279967221.

5. European Union Erasmus+ 2021-2027. Available online: https:/ / op.europa.eu/s/oTcf (accessed on 18 July 2021).

6. Crisci, M.; Di Tanna, B. Flexible Mobility for Unstable Workers: South-North Temporary Migration in Italy. Polis 2016, 30, 181-210. [CrossRef]

7. Rau, H.; Popp, M.; Namberger, P.; Mögele, M. Short Distance, Big Impact: The Effects of Intra-City Workplace Relocation on Staff Mobility Practices. J. Transp. Geogr. 2019, 79, 102483. [CrossRef]

8. De Vos, J.; Ettema, D.; Witlox, F. Changing Travel Behaviour and Attitudes Following a Residential Relocation. J. Transp. Geogr. 2018, 73, 131-147. [CrossRef]

9. Fatmi, M.R.; Habib, M.A. Modelling Mode Switch Associated with the Change of Residential Location. Travel Behav. Soc. 2017, 9, 21-28. [CrossRef]

10. Scheiner, J.; Holz-Rau, C. Changes in Travel Mode Use after Residential Relocation: A Contribution to Mobility Biographies. Transportation 2013, 40, 431-458. [CrossRef]

11. Mokhtarian, P.L.; Cao, X. Examining the Impacts of Residential Self-Selection on Travel Behavior: A Focus on Methodologies. Transp. Res. Part B Methodol. 2008, 42, 204-228. [CrossRef]

12. Stanbridge, K.; Lyons, G. Travel Behaviour Considerations during the Process of Residential Relocation. In Proceedings of the 11th International Conference on Travel Behaviour Research, Kyoto, Japan, 16-20 August 2006; pp. 16-20.

13. Welsch, J.; Conrad, K.; Wittowsky, D. Exploring Immigrants Travel Behaviour: Empirical Findings from Offenbach Am Main, Germany. Transportation 2018, 45, 733-750. [CrossRef]

14. Klinger, T. Moving from Monomodality to Multimodality? Changes in Mode Choice of New Residents. Transp. Res. Part A Policy Pract. 2017, 104, 221-237. [CrossRef]

15. Klinger, T.; Lanzendorf, M. Moving between Mobility Cultures: What Affects the Travel Behavior of New Residents? Transportation 2016, 43, 243-271. [CrossRef]

16. Burbidge, S.K. Foreign Living Experience as a Predictor of Domestic Travel Behavior. J. Transp. Geogr. 2012, 22, 199-205. [CrossRef]

17. Frändberg, L. Temporary Transnational Youth Migration and Its Mobility Links. Mobilities 2014, 9, 146-164. [CrossRef]

18. Collins, F.L. Researching Mobility and Emplacement: Examining Transience and Transnationality in International Student Lives. Area 2012, 44, 296-304. [CrossRef]

19. Glover, P. A Comparison between Domestic and International Students' Trip Characteristics: Evidence from an Australian University. J. Vacat. Mark. 2011, 17, 263-274. [CrossRef]

20. Thomas, G.O.; Poortinga, W.; Sautkina, E. Habit Discontinuity, Self-Activation, and the Diminishing Influence of Context Change: Evidence from the UK Understanding Society Survey. PLoS ONE 2016, 11, 1-16. [CrossRef]

21. Bamberg, S.; Rölle, D.; Weber, C. Does Habitual Car Use Not Lead to More Resistance to Change of Travel Mode? Transportation 2003, 30, 97-108. [CrossRef]

22. Müggenburg, H.; Busch-Geertsema, A.; Lanzendorf, M. Mobility Biographies: A Review of Achievements and Challenges of the Mobility Biographies Approach and a Framework for Further Research. J. Transp. Geogr. 2015, 46, 151-163. [CrossRef] 
23. Clark, B.; Chatterjee, K.; Melia, S.; Knies, G.; Laurie, H. Life Events and Travel Behavior. Transp. Res. Rec. J. Transp. Res. Board 2014, 2413, 54-64. [CrossRef]

24. Ajzen, I. The Theory of Planned Behavior. Organ. Behav. Hum. Decis. Process. 1991, 50, 179-211. [CrossRef]

25. Smart, M.J.; Klein, N.J. Remembrance of Cars and Buses Past: How Prior Life Experiences Influence Travel. J. Plan. Educ. Res. 2018, 38, 139-151. [CrossRef]

26. Cao, X.; Mokhtarian, P.L. How Do Individuals Adapt Their Personal Travel? A Conceptual Exploration of the Consideration of Travel-Related Strategies. Transp. Policy 2005, 12, 199-206. [CrossRef]

27. Kim, J.H.; Pagliara, F.; Preston, J. The Intention to Move and Residential Location Choice Behaviour. Urban Stud. 2005, 42, 1621-1636. [CrossRef]

28. Ettema, D.; Nieuwenhuis, R. Residential Self-Selection and Travel Behaviour: What Are the Effects of Attitudes, Reasons for Location Choice and the Built Environment? J. Transp. Geogr. 2017, 59, 146-155. [CrossRef]

29. Cao, X.; Mokhtarian, P.L.; Handy, S.L. The Relationship between the Built Environment and Nonwork Travel: A Case Study of Northern California. Transp. Res. Part A Policy Pract. 2009, 43, 548-559. [CrossRef]

30. Van Wee, B. Self-Selection: A Key to a Better Understanding of Location Choices, Travel Behaviour and Transport Externalities? Transp. Rev. 2009, 29. [CrossRef]

31. De Abreu e Silva, J. Spatial Self-Selection in Land-Use-Travel Behavior Interactions: Accounting Simultaneously for Attitudes and Socioeconomic Characteristics. J. Transp. Land Use 2014, 7, 63. [CrossRef]

32. De Abreu e Silva, J.; Morency, C.; Goulias, K.G. Using Structural Equations Modeling to Unravel the Influence of Land Use Patterns on Travel Behavior of Workers in Montreal. Transp. Res. Part A Policy Pract. 2012, 46, 1252-1264. [CrossRef]

33. Van Acker, V.; van Wee, B.; Witlox, F. When Transport Geography Meets Social Psychology: Toward a Conceptual Model of Travel Behaviour. Transp. Rev. 2010, 30, 219-240. [CrossRef]

34. Kinsella, J.; Caulfield, B. An Examination of the Quality and Ease-of-Use of Public Transport in Dublin from a New Comer's Perspective. J. Public Transp. 2011, 14, 69-81. [CrossRef]

35. Dziekan, K. Ease-of-Use in Public Transportation-A User Perspective on Information and Orientation Aspect. Ph.D. Thesis, KTH Royal Institute of Technology, Stockholm, Switzerland, 2008.

36. Bell, M.; Ward, G. Comparing Temporary Mobility with Permanent Migration. Tour. Geogr. 2000, 2, 87-107. [CrossRef]

37. Dal Fiore, F.; Mokhtarian, P.L.; Salomon, I.; Singer, M.E. “Nomads at Last"? A Set of Perspectives on How Mobile Technology May Affect Travel. J. Transp. Geogr. 2014, 41, 97-106. [CrossRef]

38. Susilo, Y.O.; Cats, O. Exploring Key Determinants of Travel Satisfaction for Multi-Modal Trips by Different Traveler Groups. Transp. Res. Part A Policy Pract. 2014, 67, 366-380. [CrossRef]

39. Ingvardson, J.B.; Nielsen, O.A. The Relationship between Norms, Satisfaction and Public Transport Use: A Comparison across Six European Cities Using Structural Equation Modelling. Transp. Res. Part A Policy Pract. 2019, 126, 37-57. [CrossRef]

40. Cats, O.; Abenoza, R.F.; Liu, C.; Susilo, Y.O. Evolution of Satisfaction with Public Transport and Its Determinants in Sweden Identifying Priority Areas. Transp. Res. Rec. 2015, 2538, 86-96. [CrossRef]

41. Wolday, F.; Næss, P.; Cao, X. Travel-Based Residential Self-Selection: A Qualitatively Improved Understanding from Norway. Cities 2019, 87, 87-102. [CrossRef]

42. Monteiro, M.M.; de Abreu e Silva, J.; Haustein, S.; Pinho de Sousa, J. Urban Travel Behavior Adaptation of Temporary Transnational Residents. J. Transp. Geogr. 2021, 90. [CrossRef]

43. Verplanken, B.; Orbell, S. Reflections on Past Behavior: A Self-Report Index of Habit Strength. J. Appl. Soc. Psychol. 2003, 33, 1313-1330. [CrossRef]

44. Aultman-Hall, L.; Roorda, M.; Baetz, B.W. Using GIS for Evaluation of Neighborhood Pedestrian Accessibility. J. Urban Plan. Dev. 1997, 123, 10-17. [CrossRef]

45. Byrne, B.M. Structural Equation Modeling with Mplus; Routledge: London, UK, 2013; ISBN 9780203807644.

46. Kaiser, H.F. An Index of Factorial Simplicity. Psychometrika 1974, 39, 31-36. [CrossRef]

47. Cronbach, L.J. Coefficient Alpha and the Internal Structure of Tests. Psychometrika 1951, 16, 297-334. [CrossRef]

48. Hinton, P. SPSS Explained; Routledge: London, UK, 2014; ISBN 9781315797298.

49. Muthén, L.K.; Muthén, B.O. MPlus User' Guide; Muthén \& Muthén: Los Angeles, USA, 2017. Available online: https://www. statmodel.com/download/usersguide/MplusUserGuideVer_8.pdf (accessed on 18 July 2021).

50. Muthén, B.; Asparouhov, T. Bayesian Structural Equation Modeling: A More Flexible Representation of Substantive Theory. Psychol. Methods 2012, 17, 313-335. [CrossRef] [PubMed]

51. Ouellette, J.A.; Wood, W. Habit and Intention in Everyday Life: The Multiple Processes by Which Past Behavior Predicts Future Behavior. Psychol. Bull. 1998, 124, 54-74. [CrossRef]

52. Cao, J.; Cao, X.; Zhang, C.; Huang, X. The Gaps in Satisfaction with Transit Services among BRT, Metro, and Bus Riders: Evidence from Guangzhou. J. Transp. Land Use 2016, 9, 97-109. [CrossRef]

53. De Vos, J. Satisfaction-Induced Travel Behaviour. Transp. Res. Part F Traffic Psychol. Behav. 2019, 63, 12-21. [CrossRef]

54. Zhao, J.; Webb, V.; Shah, P. Customer Loyalty Differences between Captive and Choice Transit Riders. Transp. Res. Rec. J. Transp. Res. Board 2014, 2415, 80-88. [CrossRef]

55. Friman, M.; Gärling, T. Frequency of Negative Critical Incidents and Satisfaction with Public Transport Services. II. J. Retail. Consum. Serv. 2001, 8, 105-114. [CrossRef] 
56. Choocharukul, K.; Van, H.T.; Fujii, S. Psychological Effects of Travel Behavior on Preference of Residential Location Choice. Transp. Res. Part A Policy Pract. 2008, 42, 116-124. [CrossRef]

57. Abenoza, R.F.; Cats, O.; Susilo, Y.O. Travel Satisfaction with Public Transport: Determinants, User Classes, Regional Disparities and Their Evolution. Transp. Res. Part A Policy Pract. 2017, 95, 64-84. [CrossRef]

58. Abdullah, M.; Dias, C.; Muley, D.; Shahin, M. Exploring the Impacts of COVID-19 on Travel Behavior and Mode Preferences. Transp. Res. Interdiscip. Perspect. 2020, 8, 100255. [CrossRef]

59. Zhang, J.; Lee, J. Interactive Effects between Travel Behaviour and COVID-19: A Questionnaire Study. Transp. Saf. Environ. 2021, 3, 166-177. [CrossRef] 